\title{
Challenges in isolating silica particles from organic food matrices with microwave-assisted acidic digestion
}

\author{
Otmar Geiss ${ }^{1} \cdot$ Ivana Bianchi ${ }^{1} \cdot$ Chiara Senaldi $^{1} \cdot$ Josefa Barrero ${ }^{1}$ \\ Received: 13 March 2019 /Revised: 16 May 2019 / Accepted: 6 June 2019 / Published online: 21 June 2019 \\ (C) The Author(s) 2019
}

\begin{abstract}
Synthetic amorphous silica is widely used in food processing as a food additive (E551) due to its properties as a flavour carrier and anti-caking agent. The direct measurement of E551 suspended or embedded in complex matrices is difficult without prior removal of the matrix components. The isolation of nanoparticles from the matrix is hence the first step towards their comprehensive characterization. Due to its complexity, matrix removal is frequently not trivial and may cause modification of the number-size distribution of the silica particles. The isolation of engineered silica nanoparticles by removal of the matrix with microwave-assisted acidic digestion is demonstrated methodologically using both monodisperse (size standards) and polydisperse (E551) particles spiked into ultrapure water and tomato sauce. For the characterization of the isolated nanoparticles, asymmetric field flow fractionation $\left(\mathrm{AF}_{4}\right)$ coupled to multi-angle laser light scattering (MALS) and inductively coupled plasma mass spectrometry (ICP-MS) were chosen. The combination of ICP-MS and ultracentrifugation allowed for the rapid and reliable measurement of the dissolved fraction of $\mathrm{SiO}_{2}$. The results show that microwave-assisted acidic digestion partially dissolves silica nanoparticles. Moreover, the digestion conditions, in particular the low $\mathrm{pH}$ value, lead to strong agglomeration of the particles. A complete deagglomeration is not achieved, even when exposing the suspension to elevated sonication doses. The consequence of these two findings is a size distribution of particles after acidic digestion that is different from the original distribution before digestion. This result may have an impact on the evaluation of whether the material is a nanomaterial according to the recommended definition of the European Commission.
\end{abstract}

Keywords Silica nanoparticles $\cdot$ E551 $\cdot$ Matrix removal $\cdot \mathrm{AF}_{4} \cdot \mathrm{ICP}-\mathrm{MS} \cdot \mathrm{DLS} \cdot$ Microwave digestion

\section{Introduction}

The use of nanoparticles (NPs), including silica nanoparticles $\left(\mathrm{SiO}_{2}-\mathrm{NPs}\right)$, has increased intensely in the last years thanks to the technical benefits they offer $[1,2]$. In addition to the wide range of non-food application fields [3], synthetic amorphous silica (SAS) is being used in food processing as a food additive (E551) due to its property as a flavour carrier and anti-caking agent $[4,5]$. Silicon dioxide (E551) is an authorized food additive

Electronic supplementary material The online version of this article (https://doi.org/10.1007/s00216-019-01964-2) contains supplementary material, which is available to authorized users.

Otmar Geiss

otmar.geiss@ec.europa.eu

1 Directorate F Health, Consumers and Reference Materials, Joint Research Centre, European Commission, Via E. Fermi, 2749, 21027 Ispra, VA, Italy in the EU and must be labelled according to the provision of Regulation (EU) No 1169/2011 [6] on food information to consumers. According to Article 18(3) of this regulation, all ingredients in the form of engineered nanomaterials shall be clearly indicated in the list of ingredients of prepacked foods marketed in the EU. To implement and enforce such a regulation, analytical methods to detect, characterize and quantify engineered nanoparticles (ENPs) are required.

Engineered nanoparticles (ENPs) in consumer products, such as cosmetics or foodstuffs, are usually suspended or embedded in complex matrices and can therefore not be directly measured without prior removal of the matrix components. Therefore, the isolation of nanoparticles from the matrix is the first step towards their comprehensive characterization. Nevertheless, due to the matrix complexity and the strong interactions between some of its components and the ENPs, matrix removal is not trivial [7], and many of the reported methods can modify the ENPs in terms of mass concentration and number-size distribution. To date, no universally 
applicable isolation and measurement method is available, and any procedure must be carefully tailored to the matrix/ material system. Several methods are described to release NPs from a sample, such as matrix destruction, extraction and/or purification. Chemical destruction of the organic components of the matrix can be achieved through acidic or alkaline digestion $[2,8-10]$ as well as through peroxy (Fenton) reaction $[11,12]$. An alternative method for the separation of chemically sensitive materials from the matrix is enzymatic digestion, in which $\alpha$-amylase for carbohydrate degradation and protease for protein degradation are added [9, 13, 14].

This study aims at systematically assessing whether microwave-assisted acidic digestion is a suitable method for the separation of $\mathrm{SiO}_{2}$ nanoparticles from matrices. The isolation of engineered silica nanoparticles by removal of the matrix with microwave-assisted acidic digestion is demonstrated methodologically using monodisperse and polydisperse (E551) particles spiked in ultrapure water and tomato sauce. For the characterization of the isolated nanoparticles, asymmetric field flow fractionation $\left(\mathrm{AF}_{4}\right)$ coupled to multi-angle laser light scattering (MALS) and inductively coupled plasma mass spectrometry (ICP-MS) were chosen. ICP-MS analysis rapidly provides reliable information on the dissolved fraction of $\mathrm{SiO}_{2}$ as it corresponds to the difference in Si-28 mass concentrations found before and after centrifugal filtration. The particle size distribution is assessed by analysing the silica extracts with $\mathrm{AF}_{4}$-MALS. Figure 1 schematically depicts the experimental procedures described in this study.

\section{Materials and methods}

\section{Chemicals}

The ultrapure water used in this work $\left(18.2 \mathrm{M} \Omega . \mathrm{cm}\right.$ at $25{ }^{\circ} \mathrm{C}$ and $\mathrm{TOC} \leq 5 \mathrm{ppb}$ ) was obtained from a Milli-Q Integral 3 System (Millipore, Billerica USA). For acidic digestion, 67$69 \%$ traceSELECT ${ }^{\mathrm{TM}}$ ultra $\mathrm{HNO}_{3}$ (Honeywell International, USA, Product Code 02650) and $30 \% \mathrm{H}_{2} \mathrm{O}_{2}$ (Sigma-Aldrich, St. Louis, USA, Product Code 95321) solutions were used. Yttrium (Product Code 01357) and silicon standards (Product

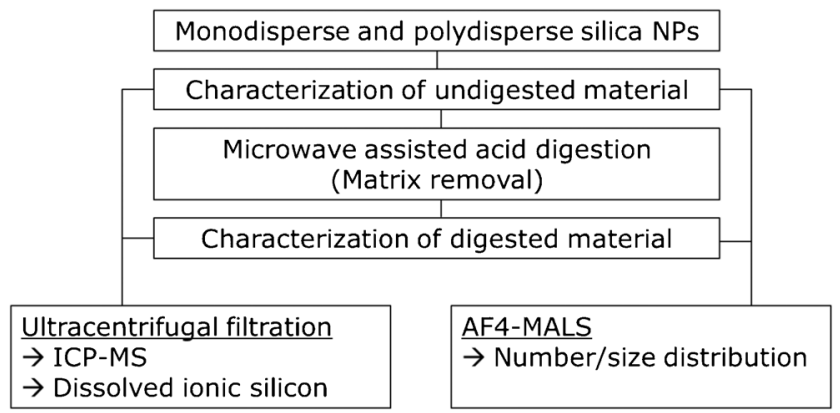

Fig. 1 Schematic of experimental procedures
Code 08729) for ICP-MS, as well as ammonium carbonate (Product Code 379999), were purchased from SigmaAldrich (Sigma-Aldrich Corp., St. Louis, USA).

\section{Silica nanoparticles (monodisperse standard suspensions)}

Size standards of $\mathrm{SiO}_{2}$ nanoparticles in water with nominal diameters of 20, 40, 60, 80, 100 and $150 \mathrm{~nm}$ (certified modal diameters and expanded uncertainties are listed in Table 1) were purchased from MSP Corporation (Shoreview, MN, USA). Stock suspensions were stored in the dark following the supplier's recommendations. Dilutions and working suspensions from the stock materials were freshly prepared each week. Before use, the concentrations of the standards, reported in Table 1, were determined/verified with ICP-MS, while the sizes were confirmed with dynamic light scattering (DLS).

\section{Food-grade synthetic amorphous silica E551 (SAS)}

The polydisperse food-grade synthetic amorphous silica (SAS) used in this study for the spiking experiments was Cab-o-Sil EH-5F manufactured by the Cabot Corporation (Boston, USA). Cab-o-Sil EH-5F is a food-grade hydrophilic fumed silica used for a wide variety of applicationsincluding as a food additive (E551), where it acts as a flavour carrier and anti-settling, thickening and anti-caking agent. Cab-o-Sil EH-5F is a high-purity food additive in compliance with applicable EU and US food additive regulations.

\section{Tomato sauce used as a real matrix for spiking experiments}

The tomato sauce used in this study for spiking experiments was purchased at a local market in Italy with the commercial name "Carrefour Passata di pomodoro".

Table 1 Certified modal diameters with their expanded uncertainties and mass concentrations of monodisperse silica standards used in this work

\begin{tabular}{ll}
\hline $\begin{array}{l}\text { Certified modal diameter } \\
(\mathrm{nm})\end{array}$ & $\begin{array}{l}\text { Determined mass concentration } \\
\left(\mathrm{mg} \mathrm{mL}^{-1}\right)\end{array}$ \\
\hline $20.2 \pm 0.5$ & 7 \\
$39.1 \pm 0.9$ & 56 \\
$61.7 \pm 1.6$ & 34 \\
$78.6 \pm 1.9$ & 16 \\
$98 \pm 2.6$ & 37 \\
$154 \pm 4$ & 76 \\
\hline
\end{tabular}




\section{Elemental analysis of silica nanoparticles by ICP-MS}

The elemental analysis was performed using a Perkin Elmer NexIon 300D quadrupole ICP-MS (Perkin Elmer, Waltham, MA, USA) equipped with an SC fast peristaltic pump. The most notable/significant interference on the major silicon isotope (Si-28) is ${ }^{12} \mathrm{C}^{16} \mathrm{O}^{+}$followed by ${ }^{14} \mathrm{~N}_{2}{ }^{+}[15]$. Studies conducted in the past showed that the highest contributions to the Si background were coming from the sample introduction system and the lab-ware used for the preparation of samples [15-17]. For this reason, a PFA-ST nebulizer, a PFA 7-mm Baffle cyclonic chamber and a ceramic T-torch, complete with a PFA/Sapphire injector, were used in this study and all samples/solutions were prepared using polymeric instead of glass lab-ware. A number of previous studies also demonstrated that the polyatomic interferences could effectively be reduced using ammonia as the reaction gas [17, 18]. Following these indications, the system was operated in dynamic reaction cell mode (DRC) at an ammonia flow of $0.8 \mathrm{~mL} \mathrm{~min}^{-1}$, with an $\mathrm{RPq}$ of 0.7 , a monitoring isotope of $\mathrm{m} / \mathrm{z} 28$ for silicon, a dwell time of $50 \mathrm{~ms}$ and an integration time of $1 \mathrm{~s}$.

Quantifications were done against yttrium $(\mathrm{m} / \mathrm{z} 89)$, used as an internal standard to compensate for changes in the signal intensity caused by changes in the spray formation. For each set of samples, a new 7-point ionic silicon calibration curve ranging from 5 to $500 \mathrm{ppb}$ was created and all samples were analysed in triplicate. Under these conditions, the limits of detection and of quantification were determined according to formulas (1) and (2):

\section{Limit of detection $(\mathrm{LoD})$}

$=3 * \mathrm{sd}($ standard deviation of 6 replicates of the lowest point in the calibration curve)/slope of the calibration curve (1)

Limit of quantification (LoQ)

$=10 * \mathrm{sd}$ (standard deviation of 6 replicates of the lowest point in the calibration curve)/slope of the calibration curve

The limit of quantification was $1.7 \mathrm{ppb}$ which is in good agreement with the findings of Aureli and co-workers [17], who determined the limit of detection under the same conditions.

\section{Impact of acidic digestion on the dissolution of particles and the formation of ionic silicon}

Among the principal objectives of the current work was to assess whether the relatively aggressive acidic microwaveassisted digestion procedure results in the complete or partial dissolution of the silica particles. This was done by digesting particles of known concentration and size, filtering the digested solution through nanoparticle-retentive centrifugal filters and analysing the presence of silicon in the filtrate. Each of these steps required optimization. The optimization procedures are described in the following.

\section{Optimization of the centrifugal filtration step-release of ionic silicon from filter membranes}

In the procedure proposed in this study, the digested and diluted solution is filtered to separate silica particles from the ionic silicon potentially released/dissolved during the digestion procedure. Amicon Ultra-4 centrifugal filters (Merck
Millipore, Cork, Ireland, product code UFC800324) with a nominal molecular weight limit of $3 \mathrm{kDa}$, corresponding to a pore size of approximately $1 \mathrm{~nm}$ [19], were used for this purpose. Before use, the centrifugal filters were tested for their release of ionic silicon from the cellulose membrane. For this purpose, $4 \mathrm{~mL}$ of ultrapure water was centrifuged at $4000 \mathrm{rpm}$ for $50 \mathrm{~min}$ at room temperature, and the content of ionic silicon in the filtrate was subsequently analysed with ICP-MS.

\section{Nanoparticle retention efficacy of the filtering membrane}

The retention efficacy of the filtering membrane was assessed by filtering suspensions of $\mathrm{SiO}_{2}$-nanoparticle standards (20 to $150 \mathrm{~nm}$, each at $200 \mathrm{ppb}$ in $1 \% \mathrm{HNO}_{3}$ ) through centrifuge filters, which retain particles down to a size of $1 \mathrm{~nm}$ while not retaining the ionic silicon, under the conditions described in the section "Optimization of the centrifugal filtration steprelease of ionic silicon from filter membranes". The amount of silicon in the filtrate was then measured with ICP-MS, and the retention efficacy was calculated by dividing the concentration of silicon in the filtrate by that in the feed suspension. A blank sample ( $4 \mathrm{~mL}$ of $1 \% \mathrm{HNO}_{3}$ ) was filtered and analysed in parallel for quality control purposes. For these tests, the filters were washed once with $1 \%$ nitric acid before use. 


\section{Microwave acidic digestion-optimization of conditions}

As unnecessarily aggressive digestion conditions could enhance the dissolution of silica nanoparticles, in this set of experiments, the minimum conditions - in terms of temperature and timenecessary to digest the sample matrix were determined.

A CEM SP-D 80 microwave digestion system (CEM Corporation, NC, USA) was used in this study. The initial digestion conditions were taken from a pre-set method for the digestion of tomato sauce. A mixture of $2 \mathrm{~mL}$ tomato sauce, $5 \mathrm{~mL}$ concentrated $\mathrm{HNO}_{3}$ and $1 \mathrm{~mL} 30 \% \mathrm{H}_{2} \mathrm{O}_{2}$ underwent digestion under the following conditions: target temperature $200{ }^{\circ} \mathrm{C}$, ramp time $5 \mathrm{~min}$, hold time $4 \mathrm{~min}$ and maximum power $300 \mathrm{~W}$. As alternatives to these standard conditions, lower digestion temperatures $\left(180{ }^{\circ} \mathrm{C}, 160{ }^{\circ} \mathrm{C}\right.$, $150{ }^{\circ} \mathrm{C}, 120^{\circ} \mathrm{C}$ and $100{ }^{\circ} \mathrm{C}$ ) and/or shorter digestion time periods (4, 3, 2 and $1 \mathrm{~min}$ ) were tested. Digestion was considered complete when the digested solution was transparent to the naked eye. All digestion vessels were equipped with Teflon ${ }^{\mathrm{TM}}$ liners.

\section{Correlation between nanoparticle size and silica dissolution at two target digestion temperatures $\left(160^{\circ} \mathrm{C}\right.$ and $\left.200^{\circ} \mathrm{C}\right)$}

Particle suspensions of each available nominal size (20, 40, $60,80,100$ and $150 \mathrm{~nm}$ ) were directly prepared in the microwave digestion tubes equipped with Teflon ${ }^{\mathrm{TM}}$ inserts. The aqueous particle suspensions were prepared in such a way that the digested and diluted suspensions (ready for ICP-MS analysis) yielded $400 \mathrm{ppb}$ each. A blank sample (2 $\mathrm{mL}$ of ultrapure water) and a control sample containing ultrapure water spiked with ionic silicon (200 ppb solution after digestion and dilution) were also prepared for quality control purposes. Digestion mixtures were completed by adding $5 \mathrm{~mL}$ of $69 \%$ $\mathrm{HNO}_{3}$ and $1 \mathrm{~mL}$ of $30 \%$ hydrogen peroxide to each tube. After 10 min of equilibration at room temperature, the samples were digested as described under the section "Microwave acidic digestion - optimization of conditions", at two different target temperatures $\left(160{ }^{\circ} \mathrm{C}\right.$ and $\left.200{ }^{\circ} \mathrm{C}\right)$. After cooling, the acidic samples were transferred from the digestion tubes into $100-\mathrm{mL}$ volumetric flasks and brought to volume with ultrapure water. This reduced the concentration of $\mathrm{HNO}_{3}$ from $69 \%$ to approximately $3.5 \%$, making the mixture suitable for both ICP-MS analysis and filtration through the Millipore Amicon filters. Yttrium, as an internal standard, was added at a concentration of $200 \mathrm{ppb}$ to the ready-to-measure suspensions. The suspensions were then analysed with ICP-MS for the total content of $\mathrm{Si}-28$. To determine the ionic content, $4 \mathrm{~mL}$ of the digested and diluted suspensions was added to an Amicon ${ }^{\circledR}$ Ultra-4 centrifugal filter device (Millipore, USA) and centrifuged for $50 \mathrm{~min}$ at $4000 \mathrm{rpm}$ (Multifuge 3 S-R, Heraeus, Hanau, Germany). The filtrate was analysed with ICP-MS.

\section{Solubility of polydisperse food-grade (E551) fumed silica under acidic digestion conditions}

In all preceding experiments, monodisperse silica nanoparticles were used to assess the dissolution of silica nanoparticles in a systematic way. In this test, however, a polydisperse foodgrade E551 was suspended and digested, and the dissolution was assessed. A suspension of $1000 \mathrm{ppm}$ was prepared in ultrapure water, ultrasound probe sonicated $(10 \mathrm{~min}$ at $24 \mathrm{~W}$, $14,400 \mathrm{~J}$ ) and then filtered through a $0.45-\mu \mathrm{m}$ PTFE syringe disc filter. An aliquot of $100 \mu \mathrm{L}$ of this suspension was transferred into a 100-mL volumetric flask, brought to volume with $1 \% \mathrm{HNO}_{3}$ and analysed with ICP-MS. A fraction of $4 \mathrm{~mL}$ of the suspension was filtered through Amicon ${ }^{\circledR}$ filters and analysed by ICP-MS for the determination of the ionic silicon before microwave-assisted acidic digestion. In addition, $100 \mu \mathrm{L}$ of the $1000 \mathrm{ppm}$ suspension was added to a digestion tube with the Teflon ${ }^{\mathrm{TM}}$ insert equipped, along with $1.9 \mathrm{~mL}$ ultrapure water, $5 \mathrm{~mL}$ of $69 \%$ nitric acid and $1 \mathrm{~mL}$ of $30 \%$ hydrogen peroxide. After 10 min of equilibration, the suspension was digested as described in the section "Correlation between nanoparticle size and silica dissolution at two target digestion temperatures $\left(160{ }^{\circ} \mathrm{C}\right.$ and $\left.200{ }^{\circ} \mathrm{C}\right)$ ". The digested suspension was probe sonicated (10 min at $24 \mathrm{~W}, 14,400 \mathrm{~J})$ and, after a 1:100 dilution, analysed with ICP-MS. For the determination of ionic silicon, $4 \mathrm{~mL}$ of the suspension was filtered through Amicon filters and analysed by ICP-MS. Two replicates were performed $(n=3)$.

\section{Impact of acidic digestion on the nanoparticle size distribution}

This second block of experiments was aimed at assessing whether acid microwave digestion of silica nanoparticles has an impact on their size distribution. This work was primarily based on the uses of asymmetric flow field flow fractionation $\left(\mathrm{AF}_{4}\right)$ coupled to a multi-angle light scattering detector (MALS) and dynamic light scattering (DLS).

\section{Dynamic light scattering (DLS)}

A Zetasizer Nano-ZS (Malvern Panalytical Ltd., Malvern, UK) was used to perform dynamic light scattering measurements. All measurements were done in triplicate immediately after preparation at $25^{\circ} \mathrm{C}$, using disposable cuvettes. The DLS settings included the automatic optimization of the measurement conditions (measurement position/depth and attenuator).

\section{Asymmetric flow field flow fractionation $\left(\mathrm{AF}_{4}\right)$-MALS}

The $\mathrm{AF}_{4}$ used for the separation and analysis of the $\mathrm{SiO}_{2}$ nanoparticles included an Eclipse Dualtec separation system from Wyatt (Wyatt Technology Europe GmbH, Dernbach, 
Germany) and an Agilent 1260 Infinity high-performance liquid chromatograph equipped with a degasser (G1322A), an isocratic pump (G1310B), an autosampler (G1329B) and a multi-wavelength detector (G1365C), all from Agilent Technologies (Agilent Technologies, Santa Clara, USA). A Dawn 8+ Heleos II multi-angle laser light scattering (MALS) detector operating with a 658-nm laser (Wyatt Technology Europe) was coupled to the fractionation system. A $90^{\circ}$ angle was used to monitor the signal during analysis. Regenerated cellulose (10 kDa) membranes were used in the Eclipse SC separation channel (153 mm length). The spacer height was $350 \mu \mathrm{m}$. The temperature of the channel was kept constant at $25{ }^{\circ} \mathrm{C}$. The eluent was a $0.25-\mathrm{mM}$ ammonium carbonate solution ( $\mathrm{pH}$ 9), prepared freshly every day. The data acquired with the MALS detector were processed using the ASTRA® 6.1 software package (Wyatt Technology Europe). The flow programme and cross-flow (x-flow) settings are included in Table 2. The detector flow was set at $0.5 \mathrm{~mL} \mathrm{~min}^{-1}$, the injection volume was $50 \mu \mathrm{L}$ and the focus flow was $1.0 \mathrm{~mL} \mathrm{~min}^{-1}$.

\section{Spiking experiments}

Spiking of ultrapure water with monodisperse NPs (80 and $150 \mathrm{~nm}$ ) followed by microwave-assisted acidic digestion All samples were directly prepared in the microwave quartz digestion tubes. Ultrapure water $(1.8 \mathrm{~mL})$ was spiked with $100 \mu \mathrm{L}$ of the $\mathrm{SiO}_{2}$ stock suspensions $(51,148 \mathrm{ppm}$ for $150 \mathrm{~nm}$ and 10,480 ppm for $80 \mathrm{~nm}$ ). To these diluted NP suspensions, $5 \mathrm{~mL}$ of $65 \%$ nitric acid and $1 \mathrm{~mL}$ of $30 \%$ hydrogen peroxide were added prior to the microwave-assisted digestion. After adding all aliquots, the samples remained at room temperature for $10 \mathrm{~min}$ for equilibration purposes. The samples were then digested under the following conditions: 5 min to reach $200{ }^{\circ} \mathrm{C}$ and held at $200{ }^{\circ} \mathrm{C}$ for $4 \mathrm{~min}$. After cooling, the acidic samples were transferred from the microwave tubes to $100-\mathrm{mL}$ volumetric flasks and filled to volume with the $0.25-\mathrm{mM}$ ammonium carbonate solution. Exactly $3 \mathrm{~mL}$ of this suspension was then transferred to $50-\mathrm{mL}$ Falcon $^{\mathrm{TM}}$ tubes and brought to a volume of approximately $20 \mathrm{~mL}$ with the $0.25-\mathrm{mM}$ ammonium carbonate solution. The $\mathrm{pH}$ of this suspension was adjusted to 9-9.5 with $1 \mathrm{M}$ and $0.1 \mathrm{M}$ sodium hydroxide solutions. Once the $\mathrm{pH}$ was set,

Table $2 \quad \mathrm{AF}_{4}$ flow programme and $\mathrm{x}$-flow setting

\begin{tabular}{lll}
\hline Time $[\mathrm{min}]$ & Description & Cross-flow $\left[\mathrm{mL} \mathrm{min}{ }^{-1}\right]$ \\
\hline $0-2$ & Elution & 1 \\
$2-3$ & Focus & \\
$3-6$ & Focus + inject & \\
$9-59$ & Elution & 1 \\
$59-69$ & Elution (membrane cleaning) & 0 \\
\hline
\end{tabular}

the $0.25 \mathrm{mM}$ ammonium carbonate solution was added to reach a final volume of $30 \mathrm{~mL}$. Immersed in an ice bath, this suspension was probe sonicated (Sonics \& Materials, Sonics VibraCell VCX-130, Inc., Newtown, CT, USA) using a 6-mm tip under various conditions (time, delivered acoustic power) with the aim of identifying the optimal sonication conditions (Table 3). The effective delivered acoustic power was determined following the approach described by Taurozzi and coworkers [20].

Sonicated suspensions were then analysed by DLS and $\mathrm{AF}_{4}$, and the sizing results were compared with nondigested/non-sonicated $(10 \mu \mathrm{L}$ of stock solution in $100 \mathrm{~mL}$ of the $0.25 \mathrm{mM}$ ammonium carbonate solution) and digested/ non-sonicated suspensions at the same theoretical concentrations.

Spiking of ultrapure water with food-grade fumed silica (E551) followed by microwave-assisted acidic digestion For the preparation of the stock solution, approximately $300 \mathrm{mg}$ of food-grade synthetic amorphous silica (SAS), as described in the section "Food-grade synthetic amorphous silica E551 (SAS)", was suspended in $25 \mathrm{~mL}$ of the $0.25 \mathrm{mM}$ ammonium carbonate solution. This suspension was then vortex stirred for $10 \mathrm{~s}$ and probe sonicated for $10 \mathrm{~min}$ at approximately $24 \mathrm{~W}$ (total energy 14,400 J). Subsequently, the suspension was filtered through a $0.45-\mu \mathrm{m}$ Millex-HV PVDF syringe filter (Merck Millipore, $25 \mathrm{~mm}$, Product Code SLHV025NB). After the filtration step, the $\mathrm{pH}$ of the suspension was approximately $\mathrm{pH} 5-6$. The $\mathrm{pH}$ was adjusted to $\mathrm{pH} 9-9.5$. In the following step, the percentage of $\mathrm{SiO}_{2}$ in the stock solution that passed through the filter (recovery) was determined with ICP-MS and was found to be approximately $80 \%$. To reach a concentration of $50 \mathrm{ppm}$ (well visible in $\mathrm{AF}_{4}$-MALS), the above suspension required an overall dilution of 1:200. This was achieved by adding $1 \mathrm{~mL}$ of the stock solution to $1 \mathrm{~mL}$ of ultrapure water, $5 \mathrm{~mL}$ of $65 \%$ nitric acid and $1 \mathrm{~mL}$ of $30 \%$ hydrogen peroxide. The samples were digested under the conditions detailed in the section "Spiking of ultrapure water with monodisperse NPs ( 80 and $150 \mathrm{~nm}$ ) followed by microwaveassisted acidic digestion". After cooling, the acidic samples were transferred from the microwave tubes to $100-\mathrm{mL}$ volumetric flasks and filled to volume with the $0.25 \mathrm{mM}$ ammonium carbonate solution. Exactly $15 \mathrm{~mL}$ of this suspension was then transferred to $50-\mathrm{mL}$ Falcon ${ }^{\mathrm{TM}}$ tubes and brought to a volume of approximately $25 \mathrm{~mL}$ with the $0.25 \mathrm{mM}$ ammonium carbonate solution. The $\mathrm{pH}$ of this suspension was adjusted to 9-9.5 with $1 \mathrm{M}$ and $0.1 \mathrm{M}$ sodium hydroxide solutions. Once the $\mathrm{pH}$ was set, the $0.25 \mathrm{mM}$ ammonium carbonate solution was added to reach a final volume of $30 \mathrm{~mL}$. Immersed in an ice bath, this suspension was probe sonicated for $10 \mathrm{~min}$ at $24 \mathrm{~W}$ (total energy $14,400 \mathrm{~J}$ ) using a 6$\mathrm{mm}$ probe tip. Sonicated suspensions were then analysed by DLS and $\mathrm{AF}_{4}$, and the results compared to non-digested/non- 
Table 3 Sonication conditions to which digested samples were exposed

\begin{tabular}{llll}
\hline Conditions & Duration [min] & Delivered acoustic power [W] & Delivered energy [J] \\
\hline Condition 1 & 3 & 24 & 4320 \\
Condition 2 & 7 & 24 & 10,080 \\
Condition 3 & 12 & 24 & 17,280 \\
\hline
\end{tabular}

sonicated ( $500 \mu \mathrm{L}$ of stock solution in $100 \mathrm{~mL}$ of the $0.25 \mathrm{mM}$ ammonium carbonate solution) and digested/non-sonicated suspensions at the same theoretical concentrations.

Spiking of tomato sauce with food-grade fumed silica (E551) followed by microwave-assisted acidic digestion The spiking suspension was prepared following the procedure described in the section "Spiking of ultrapure water with food-grade fumed silica (E551) followed by microwave-assisted acidic digestion". A defined amount $(1 \mathrm{~g})$ of tomato sauce was spiked with $1 \mathrm{~mL}$ of the E551 spiking solution. Subsequently, $5 \mathrm{~mL}$ of $65 \%$ nitric acid and $1 \mathrm{~mL}$ of $30 \%$ hydrogen peroxide were added. For the blank sample, instead of the spiked $\mathrm{SiO}_{2}-\mathrm{NP}$ suspension, $1 \mathrm{~mL}$ of ultrapure water was added. All other steps were as described in the section "Spiking of ultrapure water with food-grade fumed silica (E551) followed by microwave-assisted acidic digestion".

\section{Results}

\section{Impact of acidic microwave digestion on dissolution of particles and the release of ionic silicon}

\section{Optimization of the centrifugal filtration step}

Figure 2 depicts the concentration of silicon in the filtrate after consecutive washing cycles. It appears that the cellulose filter membranes of the Amicon® Ultra-4 centrifugal filters released ionic silicon. The maximum release was reached with the second washing cycle (total volume of $8 \mathrm{~mL}$ ultrapure water). Afterwards, the release diminished, reaching $6 \mathrm{ppb}$ in the filtrate after the 5th washing cycle. Considering that the ionic silicon content in the non-filtered ultrapure water was approximately $3 \mathrm{ppb}$, the concentration in the filtrate after the fifth washing cycle was considered low enough for the needs of this study.

In conclusion, for the assessment of ionic silicon release from silica particles, the centrifugal filters need to be washed for at least 5 washing cycles (of $4 \mathrm{~mL}$ each) before usage.

\section{Retention efficacy of filtering membrane}

The retention efficacy of the filtering membrane was assessed by filtering suspensions of $\mathrm{SiO}_{2}$ nanoparticle standards (20 to $150 \mathrm{~nm}$ ), each at $200 \mathrm{ppb}$ in $1 \% \mathrm{HNO}_{3}$, and determining the concentration of ionic silicon in the filtrate. The results in Table 4 show that independent of the particle size, the concentration of ionic silicon measured in the filtrate was equal or close to that of the blank sample. Only the filtrate of the $80-\mathrm{nm}$ particles showed a considerably higher concentration which does not, however, fit in any plausible particle size-ionic silicon concentration trend.

These results suggest that nanoparticles are fully retained independent of their size. This was an expected result, as the nominal molecular weight limit (or pore size) of the
Fig. 2 Ionic silicon released from Amicon® Ultra-4 centrifugal cellulose filter membranes after various washing cycles with ultrapure water (average concentrations $\pm \mathrm{SD}, n=3$ )

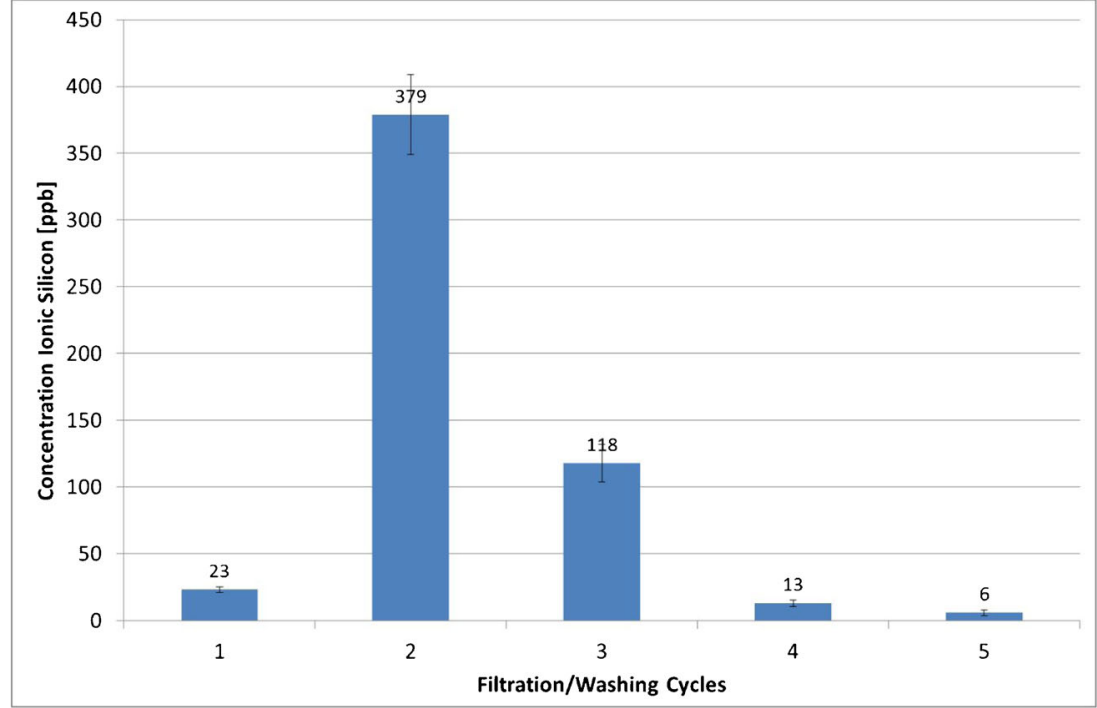


Table 4 Concentration of ionic silicon measured in the filtrate of nanoparticle suspensions of various sizes (average concentrations $\pm \mathrm{SD}, n=3$ )

\begin{tabular}{ll}
\hline Silica nanoparticle size $[\mathrm{nm}]$ & Average concentration of ionic silicon in the filtrate $\pm \mathrm{SD}(n=3)[\mathrm{ppb}]$ \\
\hline Blank (1\% nitric acid) & $22.0 \pm 0.5$ \\
$20 \mathrm{~nm}$ & $21.6 \pm 0.8$ \\
$40 \mathrm{~nm}$ & $22.6 \pm 1.2$ \\
$60 \mathrm{~nm}$ & $23.5 \pm 0.6$ \\
$80 \mathrm{~nm}$ & $32.2 \pm 0.9$ \\
$100 \mathrm{~nm}$ & $22.8 \pm 0.7$ \\
$150 \mathrm{~nm}$ & $21.1 \pm 1.0$ \\
\hline
\end{tabular}

centrifugal filters used in this study was $3 \mathrm{kDa}$, which corresponds to a particle size of below $1 \mathrm{~nm}$.

\section{Microwave acidic digestion-optimization of conditions}

Table 5 illustrates how milder digestion conditions (compared to those of the pre-set method) also lead to the complete digestion of the matrix. Digestion at $160{ }^{\circ} \mathrm{C}$ and a hold time of 4 min resulted in a completely clear digestion solution. It should, however, be noted that assessing the completeness of the digestion only by visual inspection might be associated with some uncertainty. Residual matrix components might interact with the particles in the sample and possibly interfere with their subsequent determination.

These conditions were valid only for tomato sauce. The conditions might vary for different matrices.

\section{Correlation of $\mathrm{SiO}_{2}$-NP size and dissolution propensity under acidic digestion conditions (two target temperatures $-160{ }^{\circ} \mathrm{C}$ and $200{ }^{\circ} \mathrm{C}$ )}

The aim of these measurements was to investigate the potential relationship between particle size and dissolution propensity during the digestion procedure at two different digestion temperatures $\left(160^{\circ} \mathrm{C}\right.$ and $\left.200^{\circ} \mathrm{C}\right)$. The dissolved fraction was calculated by subtracting the mass concentration of Si-28 after filtration from that before filtration. The results are expressed as a percentage according to formula (3):

Dissolved $\mathrm{SiO}_{2}[\%]$

$=\left(\right.$ mass concentration $_{\mathrm{Si} \text {,ionic }}[\mathrm{ppb}] /$ mass concentration $\left._{\mathrm{Si}, \text { total }}[\mathrm{ppb}]\right) * 100$

where (mass concentration Si,ionic $_{\text {) }}$ is the Si-28 mass concentration in the filtrate determined after ultracentrifuga-
Table 5 Completeness of digestion in relation to digestion temperature and temperature hold time at constant ramp time $(5 \mathrm{~min})$

\begin{tabular}{lll}
\hline $\begin{array}{l}\text { Digestion temperature } \\
{\left[{ }^{\circ} \mathrm{C}\right]}\end{array}$ & $\begin{array}{l}\text { Hold time at digestion temperature } \\
{[\mathrm{min}]}\end{array}$ & $\begin{array}{l}\text { Visual evaluation of the sample [clear/not } \\
\text { clear }]\end{array}$ \\
\hline 200 & 4 & Clear \\
& 3 & Clear \\
& 2 & Clear \\
& 1 & Clear \\
180 & 4 & Clear \\
& 3 & Clear \\
& 2 & Clear \\
& 1 & Clear \\
160 & 4 & Clear \\
& 3 & Not clear \\
& 2 & Not clear \\
150 & 1 & Not clear \\
& 4 & Not clear \\
100 & 3 & Not clear \\
& 2 & Not clear \\
& 1 & Not clear \\
& 1 & Not clear \\
& 1 & Not clear \\
\hline
\end{tabular}


Fig. 3 Effect of digestion temperature and particle size on $\mathrm{SiO}_{2}$ dissolution. Left $y$-axis: average dissolved fraction of silicon in percent $\pm \mathrm{SD}(n=3)$; right $y$-axis: surface area normalized relative dissolution (only for $200{ }^{\circ} \mathrm{C}$ digestion temperature)

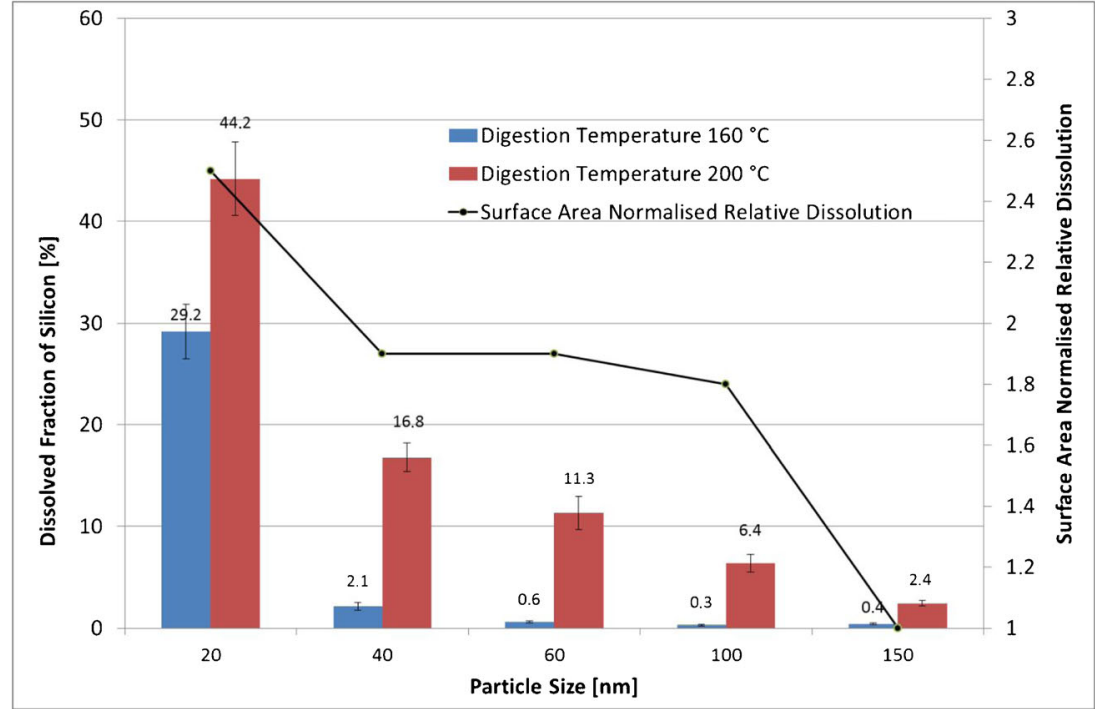

tion through Amicon filters, and (mass concentration Si,total) is the Si-28 mass concentration in the digested

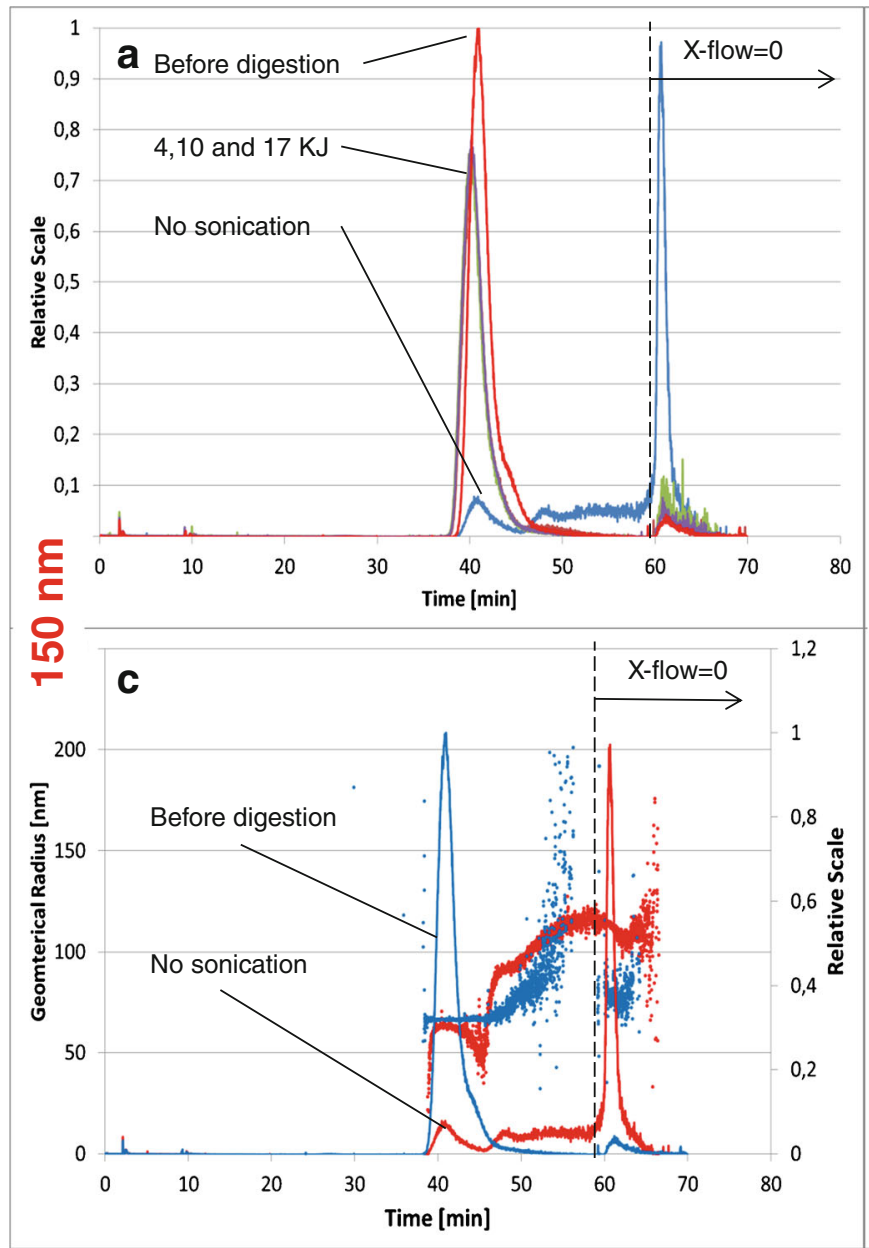

Fig. 4 a-d Upper part: overlaid $\mathrm{AF}_{4}$-fractograms (MALS) of nondigested silica NP suspensions, digested but not sonicated suspensions and digested suspensions sonicated with various amounts of energy (150 $\mathrm{nm}[\mathbf{a}]$ and $80 \mathrm{~nm}$ [b] particles). Lower part: overlaid fractograms and diluted mixture before ultracentrifugation. The concentration of silicon determined in the blank sample was



of $150 \mathrm{~nm}$ and $80 \mathrm{~nm} \mathrm{SiO}_{2}$-NP non-digested samples and digested but not sonicated samples and their respective geometric radii $(\mathrm{nm})$ recorded with the multi-angle laser light scattering (MALS) detector 


\section{$80 \mathrm{~nm}$ Particles}

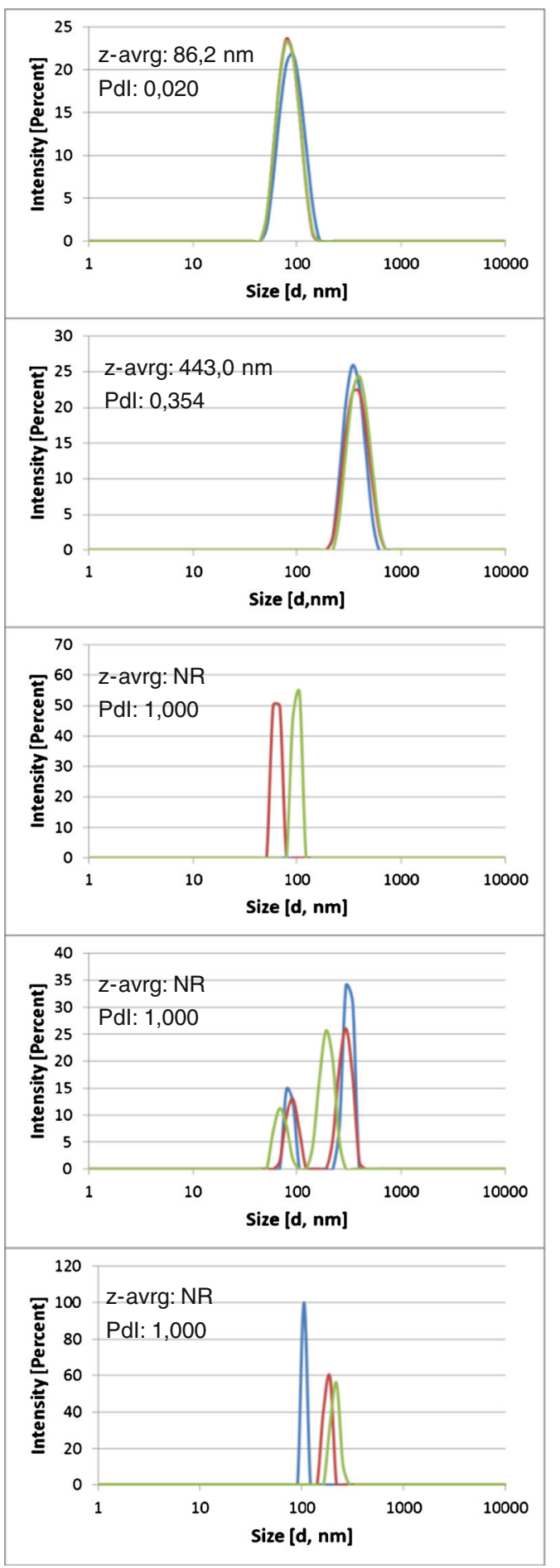

150 nm Particles
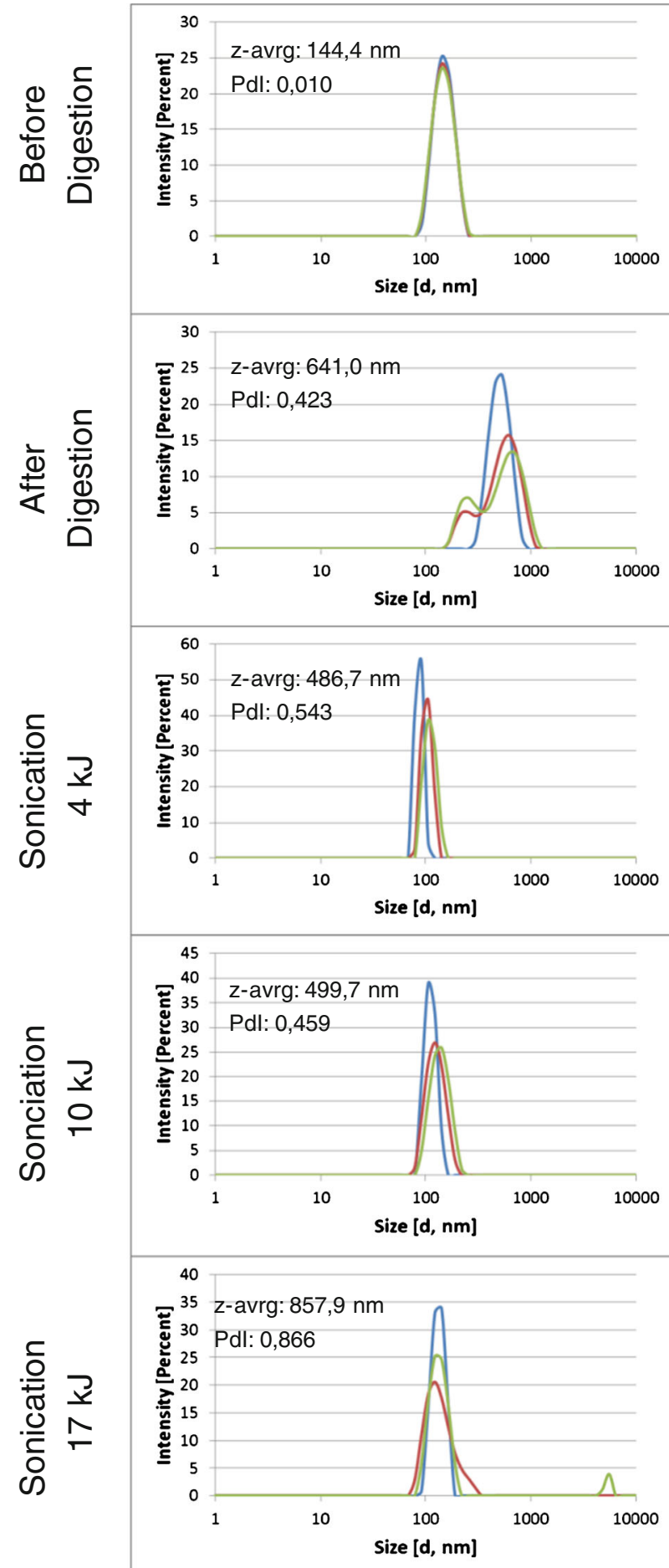

Fig. 5 DLS measurements (size distribution by intensity) for both 80-nm (left column) and 150-nm (right column) nanoparticles at various stages of the digestion procedure and at increasing sonication energy doses (each spectrum includes 3 replicate measurements). NR $=$ no result

subtracted from all test samples. Recovery of the 200-ppb silicon control sample was $96.8 \%$, indicating that no major losses occurred during the filtration step.

Figure 3 shows that particles of all sizes and at both digestion temperatures underwent dissolution. A clear trend can be observed: the digested suspension which contained smaller particles dissolved to a higher extent compared to the one with larger particles. The highest dissolution rate $(44 \%)$ was observed for particles with a nominal size of $20 \mathrm{~nm}$ at a digestion temperature of $200{ }^{\circ} \mathrm{C}$. Dissolution depends on the materials' 
Fig. 6 Fractogram of 20-ppm filtered suspension of food-grade fumed silica overlaid with $10 \mathrm{ppm}$ monodisperse size standards (60 nm, $100 \mathrm{~nm}$ and $150 \mathrm{~nm})$. The light scattering signal was recorded with MALS at $90^{\circ}$. On the left $y$-axis, the geometrical radius is displayed. The signals are normalized

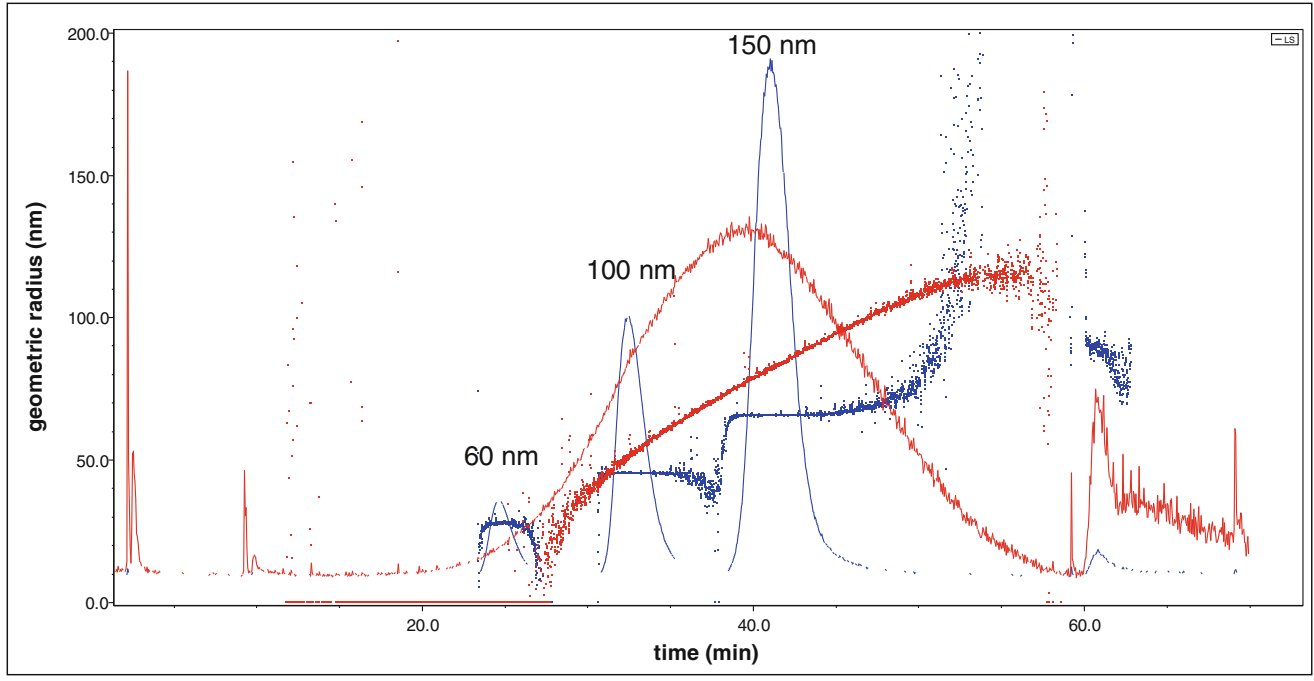

solubility within a given environment as well as the concentration gradient between the particle surface and the bulk solution phase. Consequently, the kinetics of dissolution of soluble materials is surface area dependent. Particles of a smaller size dissolve faster and to a higher extent than larger materials of the same mass [21-23]. The overall surface area of the 20$\mathrm{nm}$ particle suspension is 7.5 times higher than that of the 150 $\mathrm{nm}$ particles. The line chart in Fig. 3 depicts the surface area

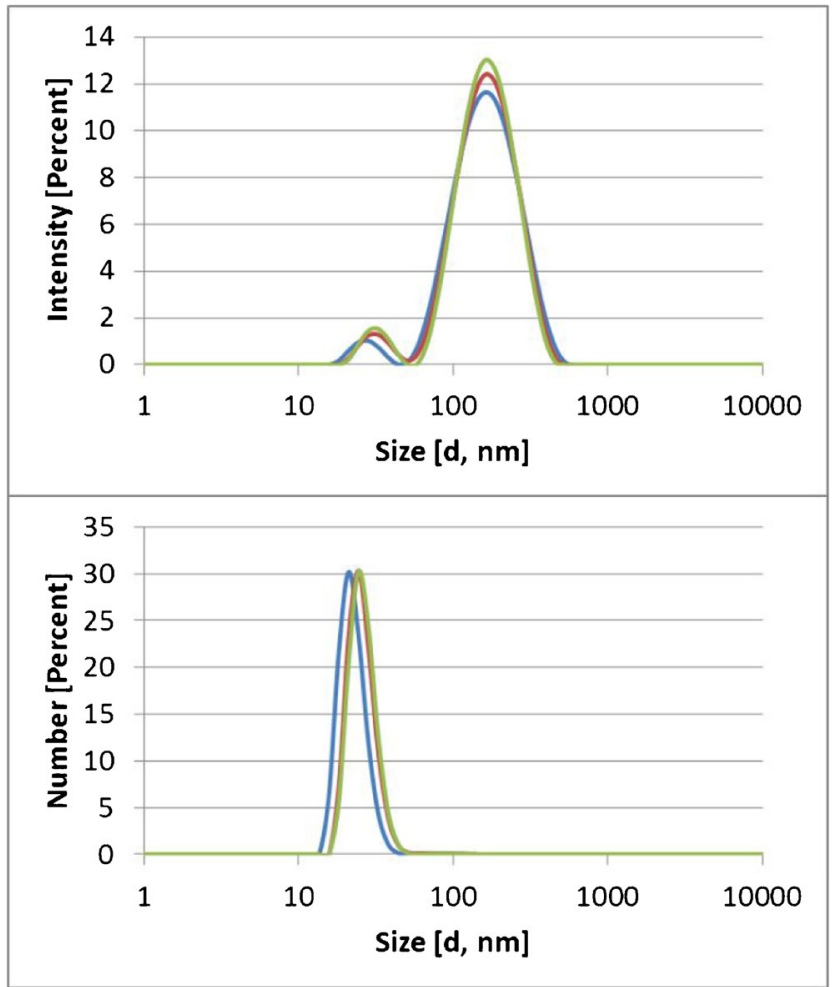

Fig. 7 DLS spectra of sonicated and filtered E551. In the upper part, the relative scattering intensity is chosen as the unit of the $y$-axis. In the lower part, the extrapolated relative number of particles is chosen as unit of the $y$-axis normalized relative dissolution at a digestion temperature of $200{ }^{\circ} \mathrm{C}$. These values were obtained dividing the dissolved fractions, expressed in percent, by the relative surface areas of each particle size, at the same mass. These values were then again normalized, assigning an arbitrary unit of 1 to the largest particles $(150 \mathrm{~nm})$. The other values express how many times more ionic silicon is dissolved compared to the 150 -nm particles. Results show that the surface area normalized dissolution of the 20-nm particles is approximately 2.5 times higher than that of the $150-\mathrm{nm}$ particles. Particles with a size of 40,60 and $100 \mathrm{~nm}$ show a constant surface area normalized relative dissolution of 1.8-1.9 times that determined for the 150 -nm particles. A possible explanation for this is the higher propensity of smaller particles to dissolve due to their energetically unfavourable higher surface-to-volume ratio [21, 24]. This finding is confirmed by Roelofs and co-workers [25] who investigated the dissolution of various types of synthetic amorphous silica.

The second important finding is that a lower digestion temperature also resulted in a lower dissolution percentage. The temperature of $160^{\circ} \mathrm{C}$ was chosen since this is the minimum temperature required to achieve a full digestion of tomato soup. The dissolution rates at $160{ }^{\circ} \mathrm{C}$ were negligible for particles with a nominal size of $>60 \mathrm{~nm}$, while for smaller particles, the dissolution was significant (almost $30 \%$ for $20-\mathrm{nm}$ particles). Giovannini et al. [26] studied the dissolution of microporous silica nanoparticles in aqueous environments at different biologically relevant $\mathrm{pH}$ values to assess their potential as a drug delivery vehicle. The authors found that nanoparticles degraded at $\mathrm{pH} 6$ and $\mathrm{pH} 7.4$, while no degradation was found at $\mathrm{pH} 4$. Under alkaline conditions, silanol groups undergo a stronger deprotonation, and the hydrolysis of $\mathrm{Si}-\mathrm{O}$ Si bonds is catalysed by nucleophilic attack of the $\mathrm{OH}^{-}$ions. In addition, Braun and co-authors [27] determined the influence of the composition of different simulated body fluids on the observed silica dissolution rates and found similar results. 


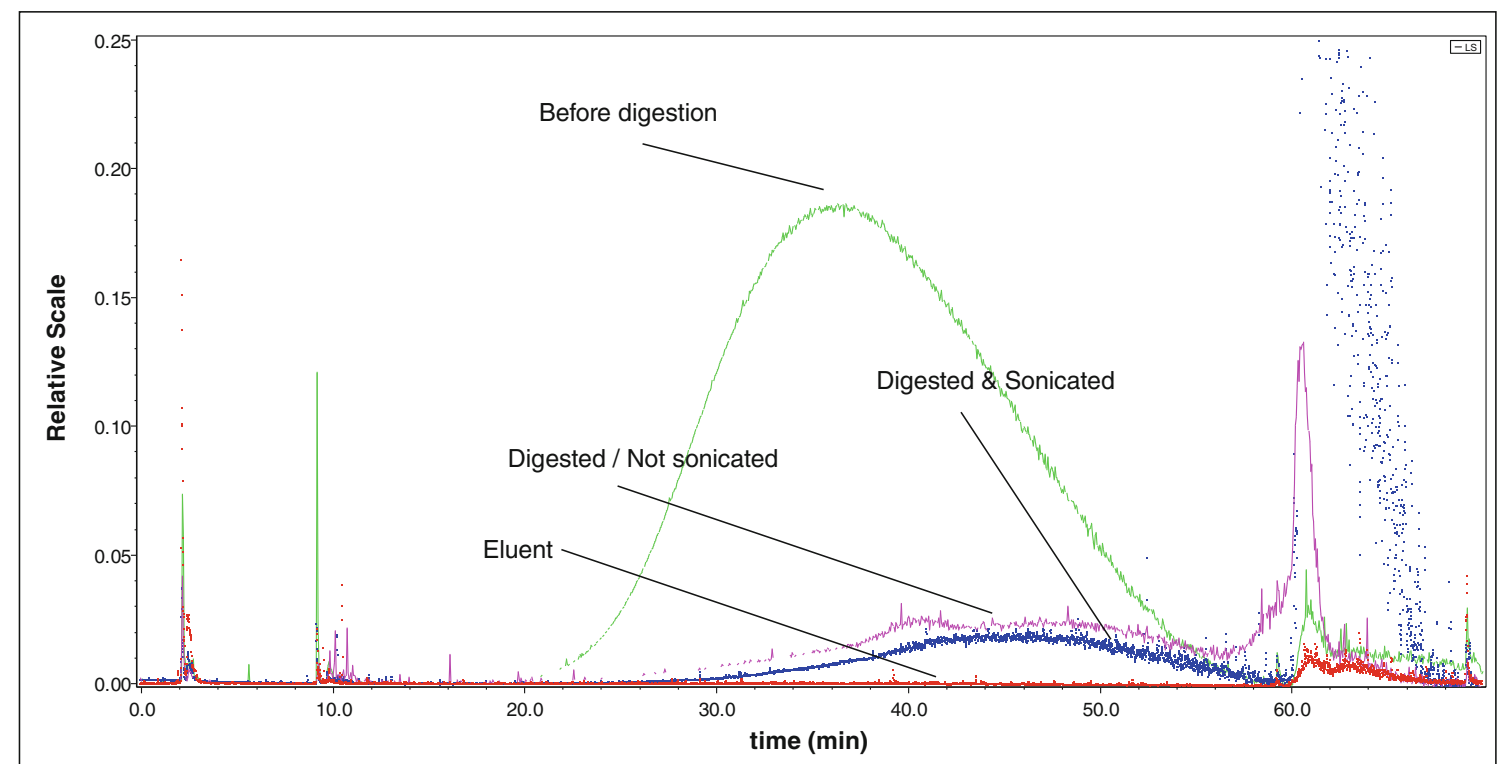

Fig. 8 Fractogram $\left(\mathrm{AF}_{4}\right.$-MALLS, $\mathrm{LS}$ angle $\left.90^{\circ}\right)$ of the E551 sample before digestion, digested but not sonicated, digested and sonicated and the eluent (0.25 mM ammonium carbonate)

The dissolution rates were found to be higher at a $\mathrm{pH}$ of approximately 7 , whereas at $\mathrm{pH} 1.6$, the dissolutions were low. These discrepancies with our findings can be explained by the conditions under which the dissolution tests were conducted. The conditions used during the microwave-assisted digestion were far more aggressive than those of the two studies described above. Moreover, during the digestion procedure in our experiments, the $\mathrm{pH}$ values cross the isoelectric point at which the particles are free of charge and tend to agglomerate/ aggregate, which might also have an impact on the dissolution properties of the particles.

\section{Solubility of polydisperse food-grade (E551) fumed silica under acidic digestion}

In the preceding section, the dissolution propensity of welldefined monodisperse silica nanoparticles was discussed. This part, in contrast, aims at investigating the dissolution of polydisperse food-grade silica. First, a suspension of $1000 \mathrm{ppm}$ was filtered through a $0.45-\mu \mathrm{m}$ PTFE disc filter. A $100-\mu \mathrm{L}$ aliquot of the filtrate was then diluted with $1 \%$ nitric acid and analysed with ICP-MS. The filtrate contained $547 \mathrm{ppb}$ silicon. In the next step, the 547-ppb suspension was ultracentrifuged



Fig. 9 Fractogram $\left(\mathrm{AF}_{4}\right.$-MALS, LS angle $\left.90^{\circ}\right)$ of tomato sauce spiked with E551 before digestion, digested but not sonicated, digested and sonicated and the blank non-spiked tomato sauce 
through 3-kDa Amicon filters. The filtrate contained $22 \mathrm{ppb}$ of silicon, which corresponded to a $4 \%$ portion of the ionic silicon in the investigated E551 fumed food-grade silica when suspended in $1 \% \mathrm{HNO}_{3}$. This finding is in good agreement with the findings of Aureli and co-authors [17], who found that ionic and particulate fractions always coexist in nanosilica (undigested) polydisperse suspensions and quantified the ionic part of various polydisperse silica suspensions in the range of $0.5-15 \%$, depending on the type of material.

For the assessment of the impact of acidic digestion on the amount of dissolved silicon, $100 \mu \mathrm{L}$ of the disc-filtered filtrate was transferred into a microwave digestion vessel along with $5 \mathrm{~mL}$ of concentrated nitric acid, $1 \mathrm{~mL}$ of $30 \%$ hydrogen peroxide and $1.9 \mathrm{~mL}$ ultrapure water. The microwavedigested suspension was then diluted to 1:1000 with $1 \%$ nitric acid and analysed with ICP-MS. The concentration of silicon was found to be $480 \mathrm{ppb}$. The missing $67 \mathrm{ppb}$ might have remained attached to the walls of the extraction vessel. The ultracentrifuged filtrate of the microwave-digested suspension contained $98 \mathrm{ppb}$ silicon, corresponding to a $20 \%$ portion of the dissolved silicon from the food-grade fumed silica. These results (2 replicates, $n=3$ ) demonstrate that during the microwave-assisted acidic digestion, a part-in particular, the smaller ones - of the particles dissolve. This action has an impact on the number-size distribution of particles.

\section{Impact of acidic digestion on the particle size distribution}

\section{Spiking experiments}

Spiking of ultrapure water with monodisperse NPs (80 and $150 \mathrm{~nm}$ ) followed by microwave-assisted acidic digestion Figure $4 \mathrm{a}$ shows the overlaid fractograms of the nondigested 150-nm nanoparticle suspension (red line), the digested but not sonicated suspension (blue line) and the digested suspensions exposed to various amounts of sonication energy (green, pink and brown lines).

After digestion and before sonication, the vast majority of particles that originally had a size of $150 \mathrm{~nm}$ were no longer visible in the fractogram. Instead, a large peak appeared when excluding the cross-flow at the end of the method for the removal of large particles left on the membrane surface of the $\mathrm{AF}_{4}$ channel. In Fig. $4 \mathrm{c}$, the geometric radii recorded with the multi-angle laser light scattering (MALS) detector are displayed for both the not-digested (blue line) and the digested but not sonicated NP suspensions (red line). The particle size distribution of the digested but not sonicated sample was no longer monodisperse; the size of the eluted particles steadily increased starting from the retention time of the main peak (at approximately $40 \mathrm{~min}$ ) to the end of the elution before the cross-flow was set to zero. The initial size of the particles (approximately $65 \mathrm{~nm}$, geometric radius) increased continuously until a plateau at approximately $120 \mathrm{~nm}$ was reached. The fact that the dominant peak appearing just after 60 min (no cross-flow) did not provide a distinct size measurement could indicate that only a small amount of very large particles were eluted at that retention time.

Figure $4 \mathrm{a}$ shows that sonication of the digested samples, the $\mathrm{pH}$ of which had previously been adjusted to approximately 9-9.5, partially re-establishes the original particle size distribution. A similar impact of the digestion and sonication can also be observed for the $80-\mathrm{nm} \mathrm{SiO}_{2}$ nanoparticles (Fig. 4b). However, the amount of sonication energy seems to have a more direct and proportional impact on the efficiency of reestablishing the original particle size distribution. The higher the sonication energy is, the closer the size distribution approaches the original non-digested suspension. It is interesting to see that a second particle population appeared at a retention time of approximately $35 \mathrm{~min}$, which decreased as the digested sample became more sonicated. The average geometric radius of this second population was approximately $65 \mathrm{~nm}$ compared to the $40 \mathrm{~nm}$ of the non-digested particles (Fig. 4d).

The general increase in the particle size after digestion and the incomplete recovery of the initial size distribution can also be observed from the DLS spectra (Fig. 5) recorded with the same procedural steps that the $\mathrm{AF}_{4}$ fractograms were acquired. Although providing less detail, the results obtained from the DLS analysis confirm that the original particle size distribution was not reached again, independent of the amount of energy that the digested suspension was exposed to. Generally, it appears that the original particle size distribution was more easily re-established by digesting and sonicating the 150-nm monodisperse nanoparticles than the 80-nm nanoparticles. After the digestion and sonication of the 80-nm nanoparticles, a number of secondary- and tertiary-size populations appeared that did not entirely disappear, even when exposed to high sonication doses.

The reason for the increase in the average particle size and the shift in the particle size distribution can be attributed to the aggregation/agglomeration behaviour of silica suspensions [4, 28]. Amorphous silica surfaces contain silanol groups. The charge of these groups determines the repulsive properties among silica particles [29], and due to protonation/deprotonation of the silanol groups, the charge depends on the $\mathrm{pH}$ of the medium in which the particles are dispersed [28]. The isoelectric point at which the particles carry no net charge, and where the aggregation is therefore the strongest, is at $\mathrm{pH} 2-3$. Peters and co-authors [4] found in their work that large silica agglomerates formed at low $\mathrm{pH}$ values and deagglomerated again at $\mathrm{pH}$ values above 7 .

The issue of $\mathrm{SiO}_{2}$ nanoparticle instability/agglomeration was also observed by Grombe and co-authors [8] during their efforts to produce reference materials for the detection and size determination of silica nanoparticles in tomato sauce. According to their findings, after the removal of organic material by acidic digestion, the stabilization of the remaining 
particle suspension by adjusting the $\mathrm{pH}$ and probe sonication, the initial particle size distribution could be partially reestablished.

\section{Characterization of food-grade polydisperse fumed silica} (E551) A 20-ppm filtered $(0.45 \mu \mathrm{m})$ suspension of the foodgrade fumed silica used in this study (red line) was injected into the $\mathrm{AF}_{4}$-MALS system together with a mixture of $(10 \mathrm{ppm}$ each) monodisperse $60 \mathrm{~nm}, 100 \mathrm{~nm}$ and $150 \mathrm{~nm}$ $\mathrm{SiO}_{2}$-NP size-standard suspensions (blue line). The fractogram in Fig. 6 shows that a relevant number of particles were in the size range below $100 \mathrm{~nm}$. The scattering intensity signal recorded with the $90^{\circ}$ MALS (red line) exhibits an almost perfectly symmetrical shape with a peak apex just below $150 \mathrm{~nm}$. However, considering that the scattering intensity is proportional to the particle diameter to a power of 6 , the majority of particles (in number) have a size smaller than $150 \mathrm{~nm}$.

This result is also supported by the DLS spectra in Fig. 7 in which both the raw scattering intensities and the extrapolated number percentages are shown for the sonicated and filtered E551 suspension. The $z$-average was $133.4 \mathrm{~nm}$, and the polydispersity index (PdI) was 0.238 . However, most particles were in the size range between 20 and $30 \mathrm{~nm}$.

\section{Spiking of ultrapure water with food-grade fumed silica} (E551) followed by microwave-assisted acidic digestion After the digestion, hard-to-remove precipitates on the walls of the digestion tubes became visible (see Electronic Supplementary Material (ESM) Fig. S1). This might be one of the reasons for the low overall recovery (approx. 25\%), which can be observed in the fractogram depicted in Fig. 8 (blue and pink lines compared to green line). The recovery rate of the digested/sonicated and digested/non-sonicated samples was determined by setting their integrated peak areas, recorded with the LS $90^{\circ}$ light scattering signal, in the elution time window starting at $16 \mathrm{~min}$ and ending at $59 \mathrm{~min}$, in relation to the peak area of the undigested sample in the same time window.

No differences in recovery were observed between the probe-sonicated digested suspension (blue line) and the nonsonicated digested (pink line) sample. When comparing the fractograms obtained from the analysis of the non-digested and the digested/sonicated suspension, it can be observed that in the digested suspension the peak-apex has shifted to the right, meaning that the suspension after digestion/sonication contained generally larger particles.

Spiking of tomato sauce with food-grade fumed silica (E551) followed by microwave-assisted acidic digestion The microwave-assisted digestion was able to remove all organic matrix components. When adding nitric acid and hydrogen peroxide without heating, a large portion of the matrix already decomposed, resulting in a yellow, not completely clear, extract. After the microwave-assisted digestion, the extracts were clear and a yellowish colour (see ESM Fig. S2). Compared to the spiked ultrapure water, the digested but not sonicated sample (red line in Fig. 9) only showed a very weak signal in the retention time range at which the particles of the E551 should be visible. The signal re-appeared, however, after probe sonication (green line). The recovery rate of the digested/sonicated sample was determined as described under section "Spiking of ultrapure water with food-grade fumed silica (E551) followed by microwave-assisted acidic digestion" and was $28.1 \pm 8.1 \%$ ( 3 replicates). In a previous study conducted by Tadjiki and co-workers [30], the recoveries of $\mathrm{SiO}_{2}$ nanoparticles were found to be in a similar range (25$39 \%$ ). In another study, in which $\mathrm{SiO}_{2}$ nanoparticles were extracted from tomato sauce, the recovery was, however, substantially higher, $>90 \%$ [31].

In all three replicates, an elution shift towards later elution times was observed, meaning that the number-size distribution shifted towards larger particles. The extent of this shift varied slightly between the three replicates, indicating that the deagglomeration did not occur in the same way for all replicates. The slight shift in size distribution confirms the findings of Wagner and co-authors [31]. In their study, they found that despite careful adjustment of the particle stabilization conditions, a slight shift was inevitable. Peters et al. [4] reached the same conclusion in their study of the dissolution, agglomeration and release of materials in the nanosize range from food with E551 during human digestion.

\section{Conclusions}

The results of this study demonstrate that microwave-assisted acidic digestion partially dissolves silica nanoparticles. The digestion conditions $(\mathrm{pH})$, moreover, lead to a strong agglomeration of the particles. A complete deagglomeration is not achieved, even when exposed to elevated sonication doses. The consequence of these two findings is that the size distribution of the particles after acidic digestion differs from the original distribution before digestion. Microwave-assisted acidic digestion is therefore unsuitable for the removal of organic matrices when the final objective is to evaluate whether the tested material is a nanomaterial or not, according to the current definition recommended by the European Commission [32]. A milder process of matrix elimination, such as enzymatic or UV treatment, should be preferred when the unaltered number-size distribution is required.

\section{Compliance with ethical standards}

Conflict of interest The authors declare that they have no conflict of interest. 
Disclaimer The information and views set out in this study are those of the author(s) and do not necessarily reflect the official opinion of the European Commission. The European Commission does not guarantee the accuracy of the data included in this study. Neither the European Commission nor any person acting on the European Commission's behalf may be held responsible for the use that may be made of the information contained therein.

Open Access This article is distributed under the terms of the Creative Commons Attribution 4.0 International License (http:// creativecommons.org/licenses/by/4.0/), which permits unrestricted use, distribution, and reproduction in any medium, provided you give appropriate credit to the original author(s) and the source, provide a link to the Creative Commons license, and indicate if changes were made.

\section{References}

1. Barahona F, Geiss O, Urban P, Ojea-Jimenez I, Gilliland D, Barrero-Moreno J. Simultaneous determination of size and quantification of silica nanoparticles by asymmetric flow field-flow fractionation coupled to ICPMS using silica nanoparticles standards. Anal Chem. 2015;87(5):3039-47. https://doi.org/10.1021/ ac504698j.

2. Mattarozzi M, Suman M, Cascio C, Calestani D, Weigel S, Undas A, et al. Analytical approaches for the characterization and quantification of nanoparticles in food and beverages. Anal Bioanal Chem. 2016;1-18. https://doi.org/10.1007/s00216-016-9946-5.

3. Barahona F, Ojea-Jimenez I, Geiss O, Gilliland D, Barrero-Moreno J. Multimethod approach for the detection and characterisation of foodgrade synthetic amorphous silica nanoparticles. J Chromatogr A. 2016;1432:92-100. https://doi.org/10.1016/j.chroma.2015.12.058.

4. Peters R, Kramer E, Oomen AG, Herrera Rivera ZE, Oegema G, Tromp PC, et al. Presence of nano-sized silica during in vitro digestion of foods containing silica as a food additive. ACS Nano. 2012;6(3):2441-51. https://doi.org/10.1021/nn204728k.

5. Athinarayanan J, Periasamy VS, Alsaif MA, Al-Warthan AA, Alshatwi AA. Presence of nanosilica (E551) in commercial food products: TNF-mediated oxidative stress and altered cell cycle progression in human lung fibroblast cells. Cell Biol Toxicol. 2014;30(2):89-100. https://doi.org/10.1007/s10565-014-9271-8.

6. Regulation (EU) No $1169 / 2011$ on the provision of food information to consumers (2011) Official Journal of the European Union, L3014/18.

7. Picó Y. Challenges in the determination of engineered nanomaterials in foods. Trends Anal Chem. 2016;84:149-59. https://doi.org/10.1016/j.trac.2016.06.004.

8. Grombe R, Charoud-Got J, Emteborg H, Linsinger TPJ, Seghers J, Wagner S, et al. Production of reference materials for the detection and size determination of silica nanoparticles in tomato soup. Anal Bioanal Chem. 2014;406(16):3895-907. https://doi.org/10.1007/ s00216-013-7554-1.

9. Deng Y, Petersen EJ, Challis KE, Rabb SA, Holbrook RD, Ranville $\mathrm{JF}$, et al. Multiple method analysis of $\mathrm{TiO} 2$ nanoparticle uptake in rice (Oryza sativa L.) plants. Environ Sci Technol. 2017;51(18): 10615-23. https://doi.org/10.1021/acs.est.7b01364.

10. Gray EP, Coleman JG, Bednar AJ, Kennedy AJ, Ranville JF, Higgins CP. Extraction and analysis of silver and gold nanoparticles from biological tissues using single particle inductively coupled plasma mass spectrometry. Environ Sci Technol. 2013;47(24): 14315-23. https://doi.org/10.1021/es403558c.

11. Gong C, Jiang J, Li D. Ultrasound coupled with Fenton oxidation pre-treatment of sludge to release organic carbon, nitrogen and phosphorus. Sci Total Environ. 2015;532:495-500. https://doi.org/ 10.1016/j.scitotenv.2015.05.131.

12. Huang YF, Huang YH. Identification of produced powerful radicals involved in the mineralization of bisphenol A using a novel UV$\mathrm{Na}(2) \mathrm{S}(2) \mathrm{O}(8) / \mathrm{H}(2) \mathrm{O}(2)-\mathrm{Fe}$ (II,III) two-stage oxidation process. J Hazard Mater. 2009;162(2-3):1211-6. https://doi.org/10.1016/j. jhazmat.2008.06.008.

13. Loeschner K, Navratilova J, Kobler C, Molhave K, Wagner S, von der Kammer F, et al. Detection and characterization of silver nanoparticles in chicken meat by asymmetric flow field flow fractionation with detection by conventional or single particle ICP-MS. Anal Bioanal Chem. 2013;405(25):8185-95. https://doi.org/10. 1007/s00216-013-7228-z.

14. Feichtmeier NS, Ruchter N, Zimmermann S, Sures B, Leopold K. A direct solid sampling analysis method for the detection of silver nanoparticles in biological matrices. Anal Bioanal Chem. 2016;408(1): 295-305. https://doi.org/10.1007/s00216-015-9108-1.

15. Klemens P, Heumann KG. Development of an ICP-HRIDMS method for accurate determination of traces of silicon in biological and clinical samples. Fresenius J Anal Chem. 2001;371(6):758-63. https://doi.org/10.1007/s002160100996.

16. Takaku Y, Masuda K, Takahashi T, Shimamura T. Determination of trace silicon in ultra-high-purity water by inductively coupled plasma mass spectrometry. J Anal At Spectrom. 1994;9(12):1385-7. https://doi.org/10.1039/ja9940901385.

17. Aureli F, D'Amato M, De Berardis B, Raggi A, Turco AC, Cubadda F. Investigating agglomeration and dissolution of silica nanoparticles in aqueous suspensions by dynamic reaction cell inductively coupled plasma-mass spectrometry in time resolved mode. J Anal At Spectrom. 2012;27(9):1540-8. https://doi.org/10.1039/ c2ja30133d.

18. H-t L, Jiang S-J. Dynamic reaction cell inductively coupled plasma mass spectrometry for determination of silicon in steel. Spectrochim Acta Part B. 2003;58(1):153-7. https://doi.org/10. 1016/S0584-8547(02)00214-8.

19. Erickson HP. Size and shape of protein molecules at the nanometer level determined by sedimentation, gel filtration, and electron microscopy. Biol Proced Online. 2009;11(1):32. https://doi.org/10. 1007/s12575-009-9008-x.

20. Taurozzi JS, Hackley VA, Wiesner MR. Ultrasonic dispersion of nanoparticles for environmental, health and safety assessmentissues and recommendations. Nanotoxicology. 2011;5(4):711-29. https://doi.org/10.3109/17435390.2010.528846.

21. Borm P, Klaessig FC, Landry TD, Moudgil B, Pauluhn J, Thomas $\mathrm{K}$, et al. Research strategies for safety evaluation of nanomaterials, part V: role of dissolution in biological fate and effects of nanoscale particles. Toxicol Sci. 2006;90(1):23-32. https://doi.org/10.1093/ toxsci/kfj084.

22. Zhang H, Chen B, Banfield JF. Particle size and $\mathrm{pH}$ effects on nanoparticle dissolution. J Phys Chem C. 2010;114(35):1487684. https://doi.org/10.1021/jp1060842.

23. Axson JL, Stark DI, Bondy AL, Capracotta SS, Maynard AD, Philbert MA, et al. Rapid kinetics of size and pH-dependent dissolution and aggregation of silver nanoparticles in simulated gastric fluid. J Phys Chem C. 2015;119(35):20632-41. https://doi.org/10. 1021/acs.jpcc.5b03634.

24. Peretyazhko TS, Zhang Q, Colvin VL. Size-controlled dissolution of silver nanoparticles at neutral and acidic $\mathrm{pH}$ conditions: kinetics and size changes. Environ Sci Technol. 2014;48(20):11954-61. https://doi.org/10.1021/es5023202.

25. Roelofs F, Vogelsberger W. Dissolution kinetics of synthetic amorphous silica in biological-like media and its theoretical description. J Phys Chem B. 2004;108(31):11308-16. https://doi.org/10.1021/ jp048767r.

26. Giovaninni G, Moore CJ, Hall AJ, Byrne HJ, Gubala V. pHdependent silica nanoparticle dissolution and cargo release. 
Colloids Surf B. 2018;169:242-8. https://doi.org/10.1016/j. colsurfb.2018.04.064.

27. Braun K, Pochert A, Beck M, Fiedler R, Gruber J, Linden M. Dissolution kinetics of mesoporous silica nanoparticles in different simulated body fluids. J Sol-Gel Sci Technol. 2016;79:319.

28. Metin CO, Lake LW, Miranda CR, Nguyen QP. Stability of aqueous silica nanoparticle dispersions. J Nanopart Res. 2011;13(2):839-50. https://doi.org/10.1007/s11051-010-0085-1.

29. Zhuravlev LT. Concentration of hydroxyl groups on the surface of amorphous silicas. Langmuir. 1987;3(3):316-8. https://doi.org/10. 1021/la00075a004.

30. Tadjiki S, Assemi S, Deering CE, Veranth JM, Miller JD. Detection, separation, and quantification of unlabeled silica nanoparticles in biological media using sedimentation field-flow fractionation. $\mathrm{J}$ Nanopart Res. 2009;11(4):981-8. https://doi.org/10.1007/s11051008-9560-3.
31. Wagner S, Legros S, Loeschner K, Liu J, Navratilova J, Grombe R, et al. First steps towards a generic sample preparation scheme for inorganic engineered nanoparticles in a complex matrix for detection, characterization, and quantification by asymmetric flow-field flow fractionation coupled to multi-angle light scattering and ICPMS. J Anal At Spectrom. 2015;30(6):1286-96. https://doi.org/10. 1039/c4ja00471j.

32. European Commission (2011) EC recommendation of 18 October 2011 on the definition of nanomaterial. (2011/696/EU). Off J Eur Union L275/38.

Publisher's note Springer Nature remains neutral with regard to jurisdictional claims in published maps and institutional affiliations. 